Sugerencia de citación: DelgadoMuñoz, B. (2020). ¿Qué hay detrás del café? Transformación agrícola, mercado de tierras y sociedades comerciales en la producción cafetera del Valle del Cauca (1900-1930). tiempo\&economía, 7(1), 97-124. doi: 10.21789/24222704.1520

\title{
¿Qué hay detrás del café? Transformación agrícola, mercado de tierras y sociedades comerciales en la producción cafetera del Valle del Cauca (1900-1930)
}

\section{What Lies behind Coffee? Agricultural Transformation, Land Market and Trade Houses in Coffee Production in Valle del Cauca (1900-1930)}

Brayan Delgado Muñoz Licenciado y Magíster en Historia de la Universidad del Valle Investigador Editorial Gá, Colombia

brayan.delgadom@gmail.com https://orcid.org/0000-0003-0123-387X

\section{RESUMEN}

Este artículo busca examinar el crecimiento de la producción cafetera en Valle del Cauca entre 1900-1930. Este fenómeno será estudiado desde los factores que lo hicieron posible en el mercado interno, centrando su análisis en dos pilares claves: (i) la expansión de la frontera agraria a nivel comercial (mercado de tierra) y (ii) el papel desempeñado por las casas comerciales especializadas en las actividades de producción, procesamiento 
y exportación del grano. Los resultados de esta investigación señalan que cada uno de los cambios implementados a nivel regional repercutió en la modernización de la agricultura. Además, se muestra que la exportación de café ayudó a arraigar la conexión con el mercado mundial, lo que a su vez derivó en nuevas oportunidades económicas para los actores (productores, comercializadores y empresarios) al acceder a mercados, créditos, puertos y mercancías. Esta construcción fue posible gracias a la información consignada en las fuentes analizadas dentro del ámbito local y regional, como los protocolos notariales que permitieron detallar las transacciones que efectuaban los actores sobre la tierra y dentro del ámbito de los negocios comerciales, así como las relaciones de crédito existentes; además de la gran variedad de fuentes contemporáneas que entregarían datos sobre el mundo de la economía cafetera.

Palabras clave: café, mercado de tierras, circuito económico, sociedades comerciales, siglo XX, historia económica.

\section{ABSTRACT}

This article studies the growth of coffee production in Valle del Cauca between 1900-1930. This phenomenon will be addressed from the factors that made it possible in the domestic market, focusing its analysis on two key pillars: (i) the expansion of the agrarian frontier at the commercial level (land market) and (ii) the role played by the specialized trade houses in the activities of production, processing and export of coffee grain. The results of this research indicate that each of the changes implemented the regional level had an impact on the modernization of agriculture. In addition, it is shown that coffee exports helped to deepen the connection with the world market, which in turn led to new economic opportunities for the actors (producers, retailers and entrepreneurs) by providing access to markets, credits, ports, and goods. This construction was possible thanks to the information contained in the sources analyzed at the local and regional levels, such as the notarial protocols used to detail the transactions carried out by the actors on the land and within the scope of commercial businesses, as well as the existing credit relationships; in addition to the great variety of contemporary sources that would provide data on the world of the coffee economy.

Keywords: Coffee, land market, economic circuit, trade houses, XX Century, economic history. 


\section{INTRODUCCIÓN}

La implementación del modelo económico liberal en el siglo XIX terminó formando un sólido vínculo con el mercado mundial -débil hasta ese momento-, lo que forjó oportunidades comerciales para la entrada de bienes intermedios en el país y, asimismo, la salida de productos de explotación primaria hacia el exterior; es decir se crearían oportunidades en una doble dirección.

El funcionamiento de este modelo económico exigió la dotación en infraestructura: comunicaciones, transporte, crédito, organizaciones de servicios/agroindustriales. ${ }^{1}$ El país impulsó el sector agrícola y transitó hacia formas de explotación agrícola-comerciales, lo que implicó un dinamismo económico de abajo hacia arriba y propició la aparición de mercados internos conectados a circuitos agroexportadores internacionales (Machado, 2002). Por consiguiente, el sector agropecuario desplegó una serie de factores que llevarían al posicionamiento de Colombia como un país exportador de materias primas, especialmente de café.

La región del Valle del Cauca se insertó en esta dinámica (crecimiento hacia fuera) gracias a su ubicación estratégica como puerta de entrada y salida al océano Pacífico por el puerto de Buenaventura, por lo que este departamento fijó sus intereses hacia la exportación de bienes primarios y convirtió al sector agroindustrial en el motor de crecimiento económico a nivel regional. De esta manera, durante las tres primeras décadas del siglo $X X$, el sector agrícola fue un elemento clave para promover los principales avances en la modernización del Valle del Cauca y la transición de su economía de un modelo de subsistencia a un enfoque comercial agroexportador. Estas transformaciones fueron estimuladas por la expansión de la economía cafetera, un factor determinante en el progreso del Valle del Cauca.

De esta forma, comprendemos que dicha transformación de la estructura agraria del departamento fue establecida a partir de cambios en la participación de varias esferas: la presencia de condiciones excepcionales para la agricultura, la estructura y la distribución de la tierra, la expansión de la frontera agraria, el mejoramiento de la infraestructura de transporte, la adopción de un modelo económico liberal, la diversificación y la

Así fue como se logró consolidar una burguesía comercial internacionalista -como lo denominó Marco Palacios-, una clase quizás como ninguna otra en el siglo pasado; fue modernizadora, de orientación internacionalista y volcada a los intercambios y al comportamiento de los volúmenes de negocios que se desprendieron de la exportación y la importación, tanto de manera individual como en sociedad (Palacios, 2009). 
especialización de la producción agrícola del departamento, ${ }^{2}$ y la estructura de multicultivos desarrollados por parte de los campesinos.

Sin desconocer la lotería de bienes ${ }^{3}$ que condicionó el buen desarrollo de la agricultura en la región, las excepcionales condiciones geográficas y climáticas del valle geográfico del río Cauca favorecieron el desarrollo de la producción agrícola. Inicialmente, la disponibilidad de suelos fértiles con un área de 188.160 hectáreas facilitaba el cultivo de diferentes productos (Boletín Estadístico, 1928). ${ }^{4}$ La composición del suelo con sustratos ricos en arcilla y minerales le dio una feracidad a la tierra del departamento, lo que permitió obtener varias cosechas en el año (Valdivia, 1992).

Otro aspecto que llevó a la transformación de la estructura agraria del departamento fue la posibilidad de transportar eficazmente los productos cultivados. Estas mejoras se dieron desde finales del siglo XIX con el establecimiento de la primera línea del ferrocarril entre Buenaventura y Córdoba (1878), la inauguración de la navegación a vapor por el río Cauca (1887) y el continuo mejoramiento de los caminos de herradura y de los pasos sobre este mismo río (Vásquez, 2001). Esta tendencia fue mucho más significativa durante la primera mitad del siglo XX: la red ferroviaria se extendió desde Buenaventura hasta Cali, luego a Palmira, después a Buga, Cartago, el viejo Caldas y Antioquia. Así mismo, la navegación a vapor en los primeros 20 años aumentó su flota, organización y capacidad de transporte (Valdivia, 1992). La mejora en el transporte resultó fundamental, puesto que redujo los costos y favoreció que el precio final de los productos fuera más bajo y llegara a más mercados de consumo.

En cuanto al funcionamiento y el desarrollo de la actividad cafetera, este trabajo profundizará en dos aspectos que explicarían por qué se logró producir un alto número de cafetos en la región. De estos aspectos se remarca, en primer lugar, la colonización de nuevos espacios aptos para la

2 Este tema se puede profundizar en el trabajo de Sánchez y Santos (2010), donde se vislumbran los factores que hicieron posible la irrupción del capitalismo agrario en el departamento.

3 Este concepto hace referencia a la posesión que tiene un lugar para generar recursos aptos para los requerimientos de un determinado momento, así como a la capacidad de algunos de ellos de generar eslabonamientos hacia atrás y adelante en el clima, la geografía y, en especial, en los problemas generados por medios de transporte costosos hasta los puertos en un momento en que cambia el contenido y los efectos del comercio internacional. Véase en Gelman (2009).

4 Del total de esta área se tiene que el $22 \%$ hacía parte de la zona plana (4.600 km2), 55 \% lo componían los terrenos altos $(11.270 \mathrm{~km} 2)$ y el terreno restante estaba compuesto por tierras onduladas, islas y arrecifes, entre otras formaciones. Sobre el total de la superficie, el $67 \%$ era utilizado para la agricultura, pastos y dehesas, y el 33 \% correspondía a tierras sin explotar que habían permanecido incultas (baldíos y ejidos). Finalmente, se debe mencionar que del total del área cultivada (67\%), $39 \%$ se localizaba en zonas cálidas, $26 \%$ en zonas templadas y $35 \%$ en zonas frías (Boletín Estadístico, 1928). 
agricultura, en los que se configuró un mercado de tierras originado en la compra y venta de tierra en el norte de la región, y, en segunda instancia, la especialización de sociedades comerciales cafeteras que funcionaron a nivel regional, estableciendo circuitos económicos que conectaron los mercados internos productores de café con mercados internacionales.

La conjugación de los factores antes mencionados hizo posible impulsar y aumentar la producción de café a nivel regional, donde la transformación agrícola incidió en las ventajas naturales del entorno al adecuarla dicha producción a una frontera agrícola mucho más productiva, gracias al esfuerzo de actores particulares, empresariales y estatales. Por su parte, el mercado de tierras fue un factor esencial para asegurar la presencia de unidades productivas de café con diversos tamaños y propietarios, puesto que estas unidades pudieron legalizar sus derechos de propiedad, generar ganancias, cultivar en mayores cantidades y expandir su frontera agrícola de manera constante. Al considerar los resultados de las sociedades comerciales cafeteras, se constata que estas permitieron canalizar toda la producción hacia los mercados de demanda (nacionales o extranjeros) a través de una serie de innovaciones, redes, créditos, tecnología y una comercialización estable de lo producido internamente.

Abordar esta problemática y preguntarnos sobre los factores que incidieron en el desarrollo cafetero a nivel regional deriva de los vacíos existentes a nivel historiográfico (regional y nacional), donde se ha sido enfático al examinar el impacto económico que ha mantenido el café en términos macroeconómicos, como señalan autores como Monsalve (1927), Arango (1982), Palacios (2002), Machado (1975) y Ocampo (1965) y, en menor medida, analizar este fenómeno desde una perspectiva regional, en la cual destacan las investigaciones de Viloria (1997), Gordillo (2001) y Ramírez (2004). Varios estudios evidencian un panorama donde el inicio del cultivo de café se dio hacia mediados del siglo XIX y se presentó un crecimiento exponencial a partir del siglo XX, gracias a la favorabilidad de Colombia para producirlo y al estímulo del mercado internacional que lo demandaba, especialmente Estados Unidos. ${ }^{5}$

En líneas generales, esta particular producción historiográfica a nivel macro presentó las novedades en los sectores sociales, económicos y políticos, las transformaciones dadas con relación a los beneficios de la producción,

5 Todo este contexto de oportunidades y de cambios, dinamizados por agentes económicos que hicieron parte del proceso, permitieron una modernización del sector agrícola, que se constituyó en el eje determinante de la integración económica, política y social del país. 
la comercialización y la exportación cafetera (Arango, 1982; Pérez, 2013), el estudio de las unidades productivas -sistema de hacienda-, las relaciones de trabajo (Machado, 1975), la formación y la consolidación de la burguesía y las etapas de la vida política (Ocampo, 2015), al igual que la indagación en la intervención estatal y las luchas agrarias (Legrand, 1988).

Referente a los estudios contemporáneos sobre el café, las investigaciones se han inclinado por analizar los factores internos ${ }^{6}$ que comprenden la expansión cafetera y los cambios ejercidos a partir de la evolución estructural de cada contexto a nivel regional (Palacios, 2002). Por su parte, este trabajo prestó especial atención a la investigación de unidades productivas y a las formas empresariales cafeteras, haciendo énfasis sobre el sistema de hacienda, las formas de organización y el funcionamiento del régimen laboral entre los siglos XIX y XX, la expansión de la frontera agraria, la distribución y la utilización de baldíos para la consolidación de algunas zonas cafeteras (Ramírez, 1999, 2001; Santos \& Sánchez, 2015) y, por último, el papel de la intermediación de empresarios en el establecimiento de circuitos y tejidos productivos (Ramírez, 2008; Viloria, 1998).

De este modo, esta investigación aportó al estudio del desarrollo del sector cafetero en la región en los primeros treinta años del siglo XX, época sobre la cual la producción historiográfica a nivel regional es parcialmente inexistente (Zuluaga, 2009). Este trabajo logró avances en cuanto al conocimiento de innovaciones claves en la economía del departamento del Valle del Cauca, donde se promovió tanto la producción cafetera en manos de miles de campesinos como el surgimiento de una clase empresarial.

A partir de la necesidad de conocer más a fondo estos elementos (mercado de tierras y sociedades comerciales cafeteras), el presente artículo se apoya en un marco teórico que permite conectar la producción de un espacio regional con un espacio internacional y comprender los factores que hicieron posible dicha conexión. Esta teoría corresponde al mercado de factores propuesto por Lewis (2008), quien afirma que la conexión de ambos espacios es posible a través de tres premisas: (i) que el espacio local tenga las condiciones propicias para producir un bien agrícola determinado, en este caso, el café; (ii) que este espacio cuente con la tierra en cantidades

6 Este tipo de investigaciones permitieron la apertura a un mundo de posibilidades sobre el abordaje de una amplia variedad de temas que hasta el momento no habían sido profundizados por la historiografía nacional y que, precisamente, se dieron a partir de un enfoque multidisciplinario de autores como Renzo Ramírez Bacca, Joaquín Viloria y Jaime Vallecilla Gordillo, referentes tanto metodológicos como teóricos; sobre todo en el tratamiento y el procesamiento de las fuentes utilizadas en cada una de sus investigaciones, desarrolladas bajo una perspectiva de la historia local. 
abundantes y de buena calidad para producir el mencionado bien agrícola, pero que además logre agenciar un proceso de privatización y de producción exitoso sobre ella, así como una configuración a razón de los registros notariales de un mercado de tierras donde se ve una activa legalización, ampliación y producción de las unidades; y (iii) que consiga crear una fuente de capital que le permita introducir mejoras a la tierra, al cultivo y a las propiedades $y$, por consiguiente, a incrementar su interés de comercialización, con lo cual puede competir en el mercado a través de la activa presencia de sociedades comerciales cafeteras, llevando el grano hacia los mercados y generando los capitales necesarios para seguir mejorando el negocio.

\section{LA EXPORTACIÓN DE CAFÉ EN COLOMBIA Y EL VALLE DEL CAUCA}

El auge cafetero en Colombia no puede concebirse sin las variables exógenas que influenciarían la demanda del mercado internacional en las primeras décadas del siglo XX. Durante este lapso de tiempo, el crecimiento de la exportación se dio con mayor fuerza sobre la década en 1910, cuando el ritmo de progresión fue elevado y constante, con bajas fluctuaciones negativas ocasionadas por la variación en la elasticidad de los precios del café colombiano en el mercado externo (Palacios, 2002), como se evidencia en la gráfica 1.
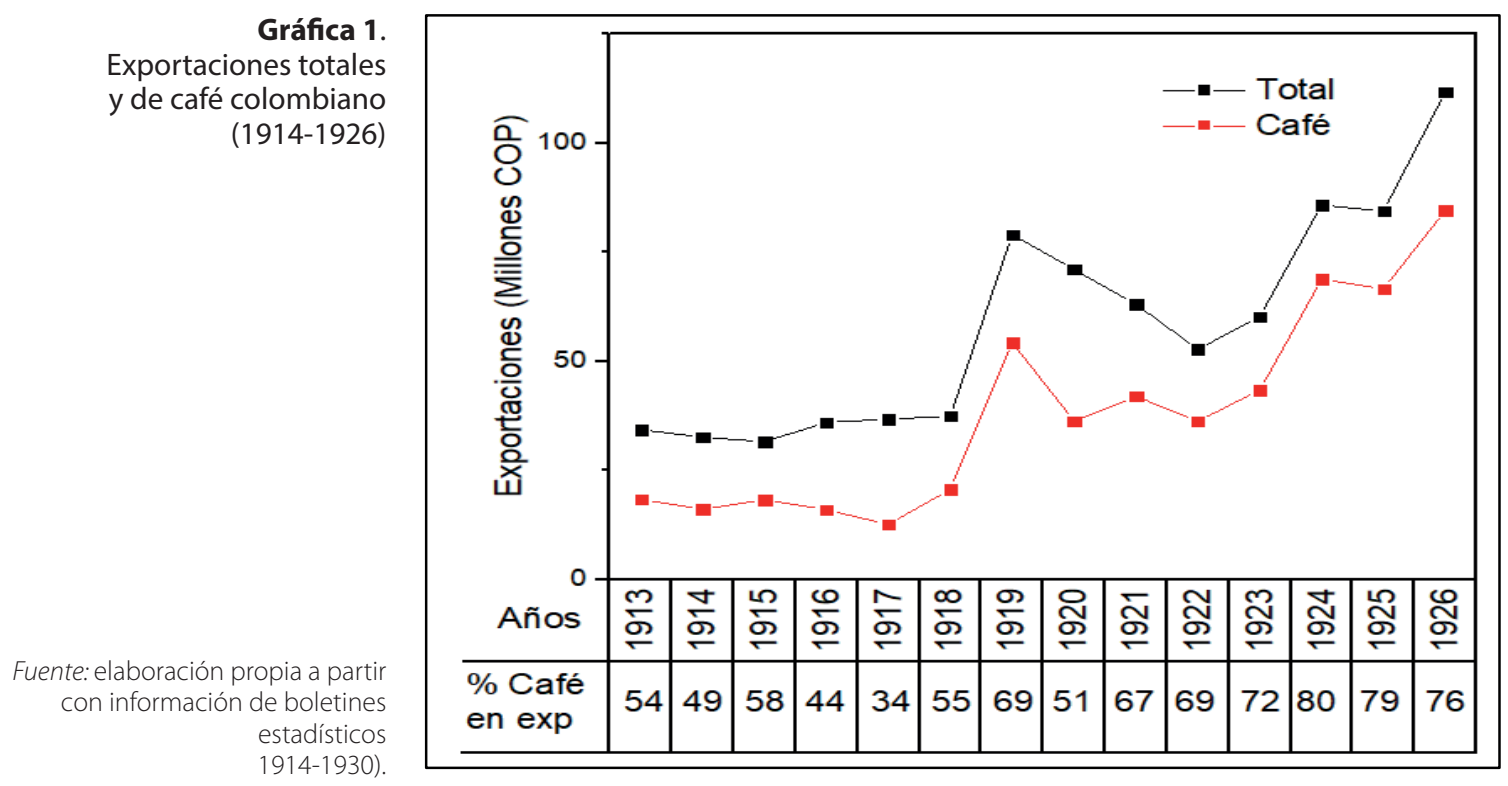
Con estos datos, se evidencia que durante la primera mitad del siglo XX las exportaciones fueron estables y su ascenso fue en promedio de 7,0 \% (Ocampo, 1965), manifestando algunos años de regresión en periodos de inestabilidad, como la primera guerra mundial. A pesar de las caídas, también hubo una rápida estabilización y desde 1920 continuó la progresión positiva hasta 1925. Sobre 1926, las exportaciones crecieron con una recuperación rápida y agresiva al acrecentarse en $67 \%$.

La participación del café colombiano en los kilogramos exportados fue vital en el sostenimiento del modelo agroexportador. Según (Palacios, 2002), el café representó el 17 \% del valor de las exportaciones totales del país, aun cuando se presentaron fluctuaciones considerables en la balanza comercial durante el último tercio del siglo XIX. Así mismo, a pesar de la crisis de precios iniciada en 1897, el valor del café ascendió hasta representar $40 \%$ de las exportaciones colombianas. No obstante, este aumento progresivo de las exportaciones del grano fue dependiente de la demanda de los diferentes países que lo consumieron. Durante la década de 1920, el café exportado por Buenaventura llegó al consumo de aproximadamente 18 países, aunque el suministro solo fue constante en cuatro países durante la misma década. En la gráfica 2 se muestra el volumen de los principales países que recibieron el grano producido en la región.

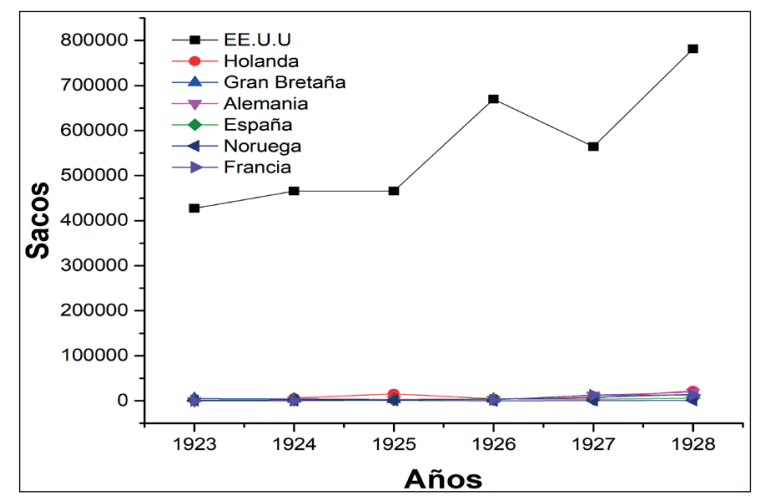

Grafica 2.

Principales destinos del café colombiano exportado durante 1923-1928

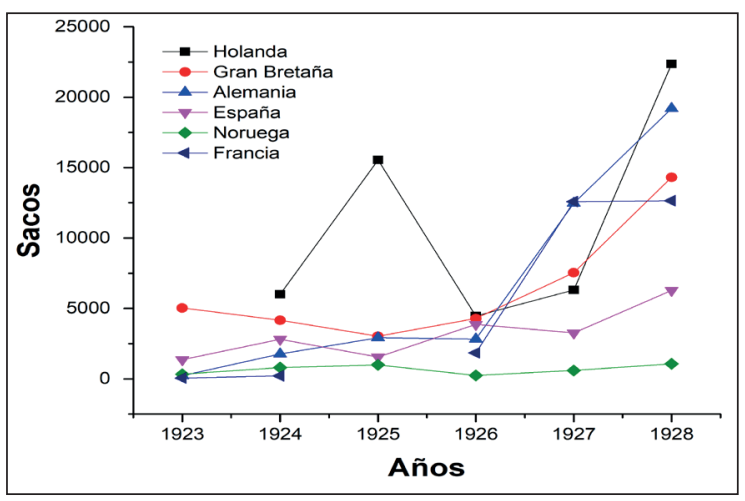

Fuente: elaboración propia a partir de boletines estadísticos (1920-1930).

Nota: la segunda gráfica no tiene en cuenta las exportaciones a Estados Unidos, lo que permite analizar mejor el comportamiento de los otros países. 
El principal comprador de Colombia fue Estados Unidos, como demuestran los datos antes presentados. El total de las importaciones de café de Norte América y Europa fue abastecido por la producción de América Central y Suramérica, siendo Brasil el primer ofertante, con el $64 \%$ del suministro del total de las importaciones a Estados Unidos, mientras que Colombia participaba con 18,3 \% del total del café importado a esta nación (Boletín Estadístico, 1925). La exportación de café crudo del territorio americano subió un poco en 1926, contrastado con el año anterior: 212.590 sacos de café crudo, avaluado en $\$ 8.049 .810$ de oro americano, contra 178.688 sacos en 1925; no obstante, el comercio de café tostado decreció en 250.000 libras, diferenciado con las cifras de 1925, año en que las exportaciones llegaron a 1.371.159 libras por valor de $\$ 532.496$, contra el año de 1926 , cuando fueron de 1.623.183 libras, avaluadas en \$ 570.594 oro americano (Boletín Estadístico, 1925).

\section{LA PRODUCCIÓN CAFETERA DEL VALLE DEL CAUCA: PROCESO DE CRECIMIENTO}

La constante demanda internacional generó que los actores se inclinarán a la exportación del grano, lo que exigió un aumento en la producción de café en el entorno regional. Por ello, el café tuvo una progresiva propagación en el departamento del Valle de Cauca, trasladándose desde la zona plana hasta las zonas de ladera, desplazando al auge cacaotero de finales del siglo XIX. De esta manera, la expansión cafetera se inició en la zona plana del territorio hacia el año 1880 y para las primeras décadas del siglo XX se propagó hacia la zona montañosa y el norte de la región (Monsalve, 1927) (figura 1).

Posteriormente, se experimentó un periodo de alza durante las primeras décadas del siglo XX, vinculado al establecimiento de destacadas unidades de explotación agrícola y al surgimiento de una nueva forma de administración y explotación agroindustrial bajo la racionalidad empresarial. En este escenario, las innovaciones no solo se dieron en la producción cafetera, sino que también se manifestaron en el procesamiento de su fruto; fue así como se establecieron negocios comerciales y se crearon fábricas agroindustriales y trilladoras en los principales centros comerciales de este departamento. 


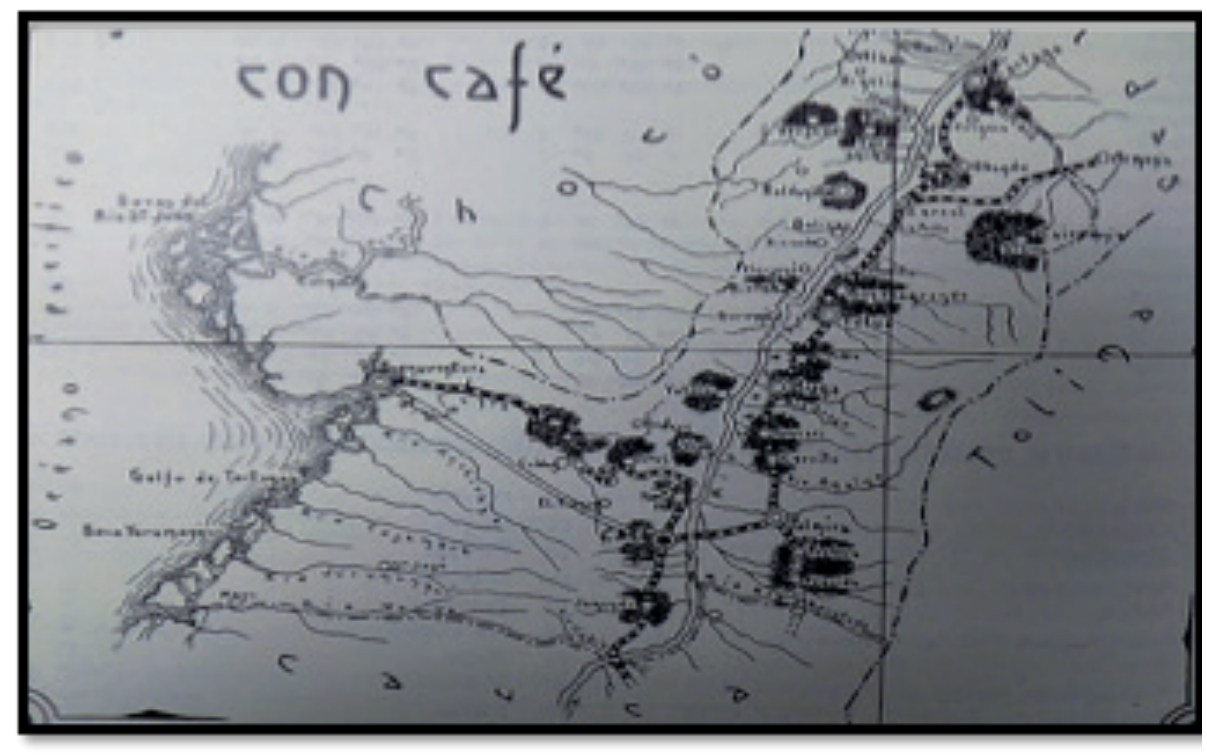

En cuanto a la propagación del grano por el departamento del Valle del Cauca, se tiene en cuenta que el crecimiento del café se dio de 1895 a 1930, cuando aumentó el área de cafetos plantados de 558.000 árboles, a finales del siglo XIX, a 9.050.102, en 1915, es decir, el incremento fue de $1.522 \%$. Sobre la década de 1930, cuando se llegó al punto más alto, se alcanzó un total de 24.611.730 árboles cultivados, un incremento de 171 \% (Monsalve, 1927). En términos generales, el café fue el cultivo de mayor crecimiento en área sembrada en todo el sector agrícola.

La intensificación en el volumen de la producción cafetera se debió a la asignación y la ocupación de zonas que hasta la primera década del siglo XX no habían sido destinadas a prácticas agrícolas. Fue así como el café se expandió gracias a los esfuerzos en la consolidación y la ampliación de la frontera agraria en la zona norte del Valle del Cauca (Boletín Estadístico, 1928. p. 139). La colonización de las cordilleras para el cultivo de café fue evidenciada por Carlos Durán Castro (1928) en un artículo en el que resalta las bondades del cultivo de café a nivel regional, además de señalar los aspectos que lo harían tener un porvenir brillante:

"El café tiene un porvenir muy brillante y un campo muy grande de expansión debido a que los mercados mundiales van creciendo cada día para el grano colombiano y aunque dispone el departamento extenso y muy adecuados terrenos en ambas cordilleras para su cultivo. Actualmente hay una activa colonización sobre ambas cordilleras hecha
Figura 1.

Mapa de las zonas productoras de café en el Valle del Cauca en 1915
Fuente: tomado de Monsalve (1927). 
Gráfica 3.

Municipios productores de café por número de árboles principalmente de café, maíz y pasto. Sobre el porvenir del café se puede ser optimista sin reservas a pesar de las fluctuaciones que necesariamente habrá de soportar su precio (Castro, 1928, p. 135)".

Con base en una nueva administración del territorio y la creación de nuevos municipios, se propagó el cultivo de café por todo el departamento, aunque entre 1910 y 1920 no existía ningún municipio en la región que no tuviera cultivos de café, desde la zona plana, alta, caliente y fría (Monsalve, 1927). La gráfica 3 presenta la cantidad de cafetos cultivados en cada municipio del departamento del Valle del Cauca para el año 1927; obsérvese el aumento de la producción de 9.050 .102 de árboles en toda la región. cultivados (1927)

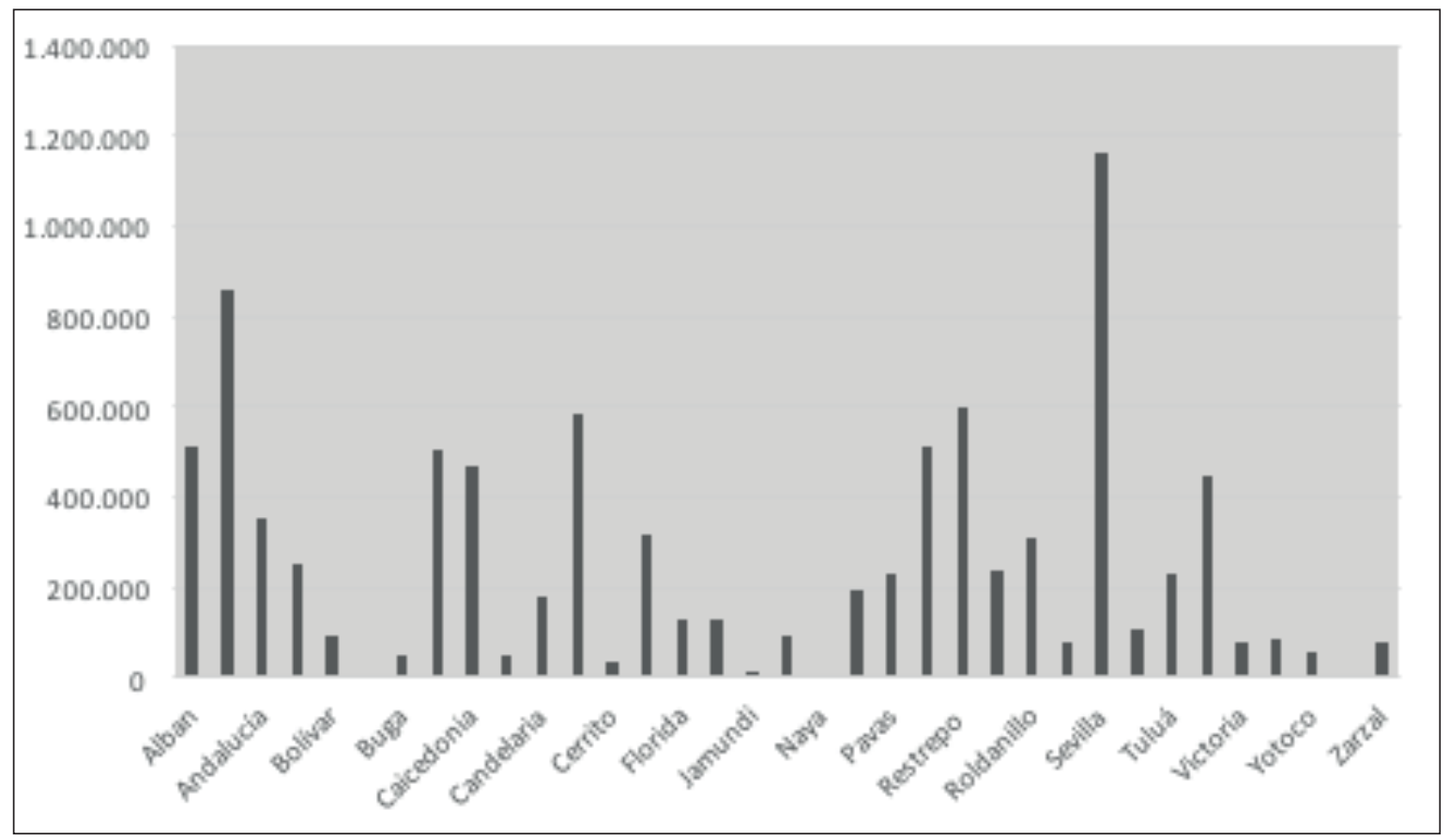

Fuente: elaboración propia a partir de los datos suministrados por Monsalve (1927, pp. 560-584).
La productividad manifestada de la economía cafetera del país aumentó $200 \%$ en 1930 si se tiene en cuenta que el rendimiento pasó de 1.069 sacos (60 kilogramos) en 1913 a 3.454 a finales de la década de los años veinte. Este esparcimiento repercutió en el aumento de la producción cafetera a nivel regional: en Antioquia se multiplicó por 19,5, en Caldas por 73,4 y en el Valle del Cauca aumentó 5,7 veces, lo que para el Valle del Cauca evidencia un promedio más conservador frente al aumento de los otros departamentos productores. 
El auge en la producción cafetera dependió generalmente del esfuerzo de iniciativas campesinas que encontraron en el café la base para subsistir y sacar adelante la economía familiar (Arango, 1977). El progreso de la economía cafetera a nivel regional hizo que para 1913 la producción interna aportara a la producción nacional el 4,6 \% del total, mientras que en 1930 esta cifra saltó a 10,2 \%. Este incremento de cerca de 6 puntos porcentuales en menos de diez años se dio gracias al volumen obtenido de las cosechas anuales, que siguió su crecimiento como resultado de la ampliación en el área productiva, evidenciado en el crecimiento del área cultivada en la década del veinte. Lo anterior fue el resultado de la introducción de 15 millones de nuevas plantaciones de café esparcidas por todo el territorio del valle geográfico del río Cauca. El resumen de esta economía cafetera entre los años 1915 y 1930 se resume en la tabla 1.

\begin{tabular}{|c|c|}
\hline Variable & Cifras \\
\hline Municipios productores de café & 35 \\
\hline Municipios no productores de café & 0 \\
\hline Plantaciones & 2.987 \\
\hline Cafetos de nueva producción & 15.556 .478 \\
\hline Cafetos de anterior producción & 9.055 .252 \\
\hline Total de cafetos & 24.611 .730 \\
\hline Despulpadores & 1.718 \\
\hline Trilladores & 3 \\
\hline
\end{tabular}

Tabla 1.

Resumen de la producción de café en el valle del cauca, $1915-1930$

Fuente: elaboración propia a partir de los datos cuantitativos en Monsalve (1927, p. 581).

Los datos presentados en la tabla 1 legitiman el crecimiento en la productividad en la economía cafetera a nivel regional, donde se superó las cifras de cafetos y el área plantada presentada entre 1880 y 1920 (etapa de despegue). Así, en 1930 la importancia de esta actividad se vio reflejada en la ampliación y consolidación del cultivo del café, puesto que las plantaciones por cafeto aumentaron $160 \%$ en promedio, frente a la década anterior. A su vez, esto llevó a que el sector demandara la implementación de algunas innovaciones (máquinas para el procesamiento, despulpadoras y trilladoras) para facilitar el procesamiento y el beneficio del grano de café.

\section{TIERRA Y MERCADO}

Un elemento clave para la transformación de la producción agrícola que tuvo el departamento se dio a partir de la estructura y la distribución de la tierra. Básicamente, entre 1900 y 1930 el departamento del Valle del 
Cauca atravesó un período de fragmentación de grandes extensiones de tierras (indivisos), en continuidad de lo acaecido desde el siglo XIX. Como lo evidencia Londoño:

"A la destrucción de las unidades productivas debemos agregarle las reformas de medio siglo, especialmente la abolición de la esclavitud y la desamortización de bienes de manos muertas. La libertad de los esclavos obligó a los grandes propietarios a implementar otras formas de sujeción de la mano de obra. La alternativa más viable fue el sistema de arrendamiento, que se había comenzado a establecer desde la segunda mitad del siglo XVII y en la nueva coyuntura se volvió imprescindible (Londoño 2003, p. 416)".

La colonización de nuevos espacios, principalmente en zonas de cordillera; la distribución de baldíos nacionales, departamentales y municipales a cultivadores ya asentados en sus respectivos poblados (Quejada, 2016); la venta de tierras y mejoras por parte de compañías colonizadoras (Londoño, 1993); la legalización de derechos de propiedad tanto a colonos como a campesinos ya radicados, al igual que a empresarios, compañías territoriales y entes estatales (Quejada, 2016); y la dinamización del mercado de tierras mediante la existencia de múltiples transacciones de compraventas y traspasos entre los actores particulares, generaron una movilización de la tierra importante en la región ante el cambio de la antigua estructura de la tenencia de la tierra. ${ }^{7}$

Lo anterior indica que el factor tierra era sumamente móvil en aquellos años, lo cual permitió ampliar de forma constante la frontera agrícola, hacer posible la presencia de distintos tipos de unidades $y$, a su vez, de distintos tipos de actores (colonos, empresarios, comerciantes, Estado, etc.). Por su parte, la dinamización del movimiento de tierras fue un factor fundamental para la expansión de la frontera agraria. En este proceso intervinieron dos clases de estímulos: (i) la necesidad de buscar sustento y asegurar un bien por parte de miles de campesinos provenientes de Antioquia y del viejo Caldas y (ii) la posibilidad de generar excedentes económicos a partir de la venta de productos agrícolas y pecuarios, tanto a mercados locales como a sociedades comerciales que los direccionaban hacia el exterior.

Uno de los procesos más relevantes de expansión de frontera agraria fue el acontecido en la zona norte del departamento (Sevilla, Caicedonia y

Esta movilidad puede ser observada a través de la revisión de la fuente empírica en el Archivo Histórico de Cali y las Notarías Primera de Sevilla y de Zarzal (Valle del Cauca). 
Zarzal), derivado de los procesos de colonización Antioqueña, donde la ocupación del espacio se desarrolló de manera espontánea y dirigida. Con ello, además, se fundaron varios centros poblacionales (Londoño, 1993). Esto se dio como resultado de contar con tierras disponibles (entre terrenos baldíos y terrenos privados bajo grandes concesiones territoriales) en distintos pisos térmicos y con abundantes recursos naturales que asegurarían subsistencia e ingresos (Valdivia, 1992). Otro aspecto fue la posibilidad de acceder $y$, principalmente, conservar los derechos de propiedad en forma de títulos sobre las tierras por parte de los actores, gracias a la presencia del Estado, de una compañía colonizadora -Burila- y de la creación de un órgano de control, repartición y deslinde de tierras como la Junta Pobladora de Sevilla (Quiceno, 2007). No obstante, el motor de la expansión de la frontera agrícola -particularmente en Sevilla- que se dio con la expansión del cultivo de café, fue el hecho de que la demanda del producto se hizo continua y aumentó de manera constante.

La economía de municipios como Sevilla empezó a girar en torno a este producto debido a la favorabilidad de cultivarlo en los pisos térmicos fríos y a las ganancias derivadas de la compra del grano por parte de casas comerciales ubicadas en Sevilla, Cali o Manizales, que, a su vez, daban acceso a dos cosas importantes para sus cultivadores: mercancías y crédito ${ }^{8}$. Recordemos que el café producido en Sevilla además fue beneficiado por los intentos del Estado por mejorar la agricultura departamental en investigación, mejora de terrenos, abonos y capacitación (Santos \& Sánchez, 2010), el establecimiento de circuitos comerciales y de transporte para la movilización de los productos cultivados hacia el eje de procesamiento y el almacenamiento del grano en Cali y hacia la puerta de salida al exterior, que era el puerto de Buenaventura (Monsalve, 1927).

Del proceso de apertura en la colonización de estos territorios se creó un mercado de tierras en el municipio de Sevilla durante el periodo de 1912-1926, el cual fue bastante dinámico, variado, monetizado, flexible y dotado de crédito (2.409 transacciones). Si se observa este mercado a nivel general, se obtienen tres puntos básicos de interés: (i) su existencia a partir de un proceso de colonización, explotación y legalización de la propiedad del suelo; (ii) la presencia del cultivo del café y un interés constante por cultivarlo; y (iii) la presencia de actores de diversa procedencia y diferente

8 Protocolos notariales de hipoteca y de venta de mercancías en Notaría Primera de Sevilla (en adelante NPS), Notaría Única de Zarzal (en adelante NUZ) y de Notaría Única de Caicedonia (en adelante NUC). 
poder adquisitivo en función de los movimientos del mercado -compra o venta-, siempre en procura de obtener una propiedad para aquellos que no la tenían, ensanchar y mejorar la propiedad para los que la tuvieran o lograr ganancias al hacer operaciones de compra, venta o de préstamos de dinero sobre hipoteca.

Este mercado contó con cuatro actores principales: la Empresa Burila, la Junta Pobladora de San Luis (posteriormente de Sevilla), los colonos y los comerciantes. Cada uno intervino en una o más tipos de operaciones, comprando o vendiendo; sin embargo, también se situaron en el punto intermedio, que era conceder créditos para que unos actores hicieran compra o venta. Para estos últimos, el interés que primaba era la ganancia o el mejoramiento de la propiedad, buscando aumentar su productividad, especialmente de los cultivos de café. Estos actores generaron varios tipos de operaciones dentro de este mercado, profundizando en tres: compraventa, crédito hipotecario y adjudicación. Cada una de estas operaciones fue significativa dentro del mercado y fueron similares en algunas cuestiones (tipos de propiedades que manejaron, utilización del dinero y del crédito) y diferentes en otras (actores involucrados, ritmo de crecimiento o decrecimiento). Así mismo, cada uno de estos actores tuvo dinámicas y características propias. En todas estas operaciones se tiene la presencia de distintos actores y valores; los ciclos que comparten son parecidos y se distancian en el tiempo, algunas operaciones cayeron y otras aumentaron. Todas estas operaciones se apoyaron en un elemento común: la seguridad de los derechos de propiedad, como se puede analizar en los diferentes tipos de operaciones presentados en la tabla 2.

De esta manera, el mercado de tierras permitió la base sobre la cual se pudiera legalizar la propiedad, ampliar la frontera agrícola y aumentar la producción de café en Sevilla. Claramente, dentro de esta dinámica se puede inferir que el acceso a la tierra fue un proceso democrático, no exclusivo de empresarios territoriales, que logró evidenciar una frontera abierta para acceder a los derechos de propiedad y un mercado abierto a todos los actores (colonos, Burila, Junta Pobladora y comerciantes), en donde cada uno orientó sus intereses al mercado (interés de ganancia, acceso a la propiedad o de acceso a fuentes de crédito) sin entrar en conflictos y obteniendo bienestar. 
Tabla 2.

Total de operaciones del mercado de tierras en Sevilla, 1912-1926

\begin{tabular}{|c|c|c|c|c|c|}
\hline Año & Compraventa & Crédito hipotecario & Adjudicaciones & Permutas & Total \\
\hline 1912 & 20 & - & 19 & - & 39 \\
\hline 1913 & 4 & - & 4 & - & 8 \\
\hline 1914 & 6 & - & - & - & 6 \\
\hline 1915 & 32 & - & 2 & - & 34 \\
\hline 1916 & 180 & - & 1 & 1 & 182 \\
\hline 1917 & 137 & 12 & 22 & 2 & 173 \\
\hline 1918 & 143 & 13 & 1 & 1 & 158 \\
\hline 1919 & 378 & 12 & 5 & 6 & 401 \\
\hline 1920 & 354 & 11 & & 2 & 367 \\
\hline 1921 & 98 & 33 & 6 & 7 & 144 \\
\hline 1922 & 84 & 22 & 9 & 7 & 122 \\
\hline 1923 & 80 & 23 & 15 & 7 & 125 \\
\hline 1924 & 162 & 49 & 18 & 4 & 233 \\
\hline 1925 & 175 & 47 & 3 & 8 & 233 \\
\hline 1926 & 134 & 41 & 1 & 8 & 184 \\
\hline Total & 1987 & 263 & 106 & 53 & 2.409 \\
\hline$\%$ total & 81 & 11 & 4 & 2 & - \\
\hline
\end{tabular}

\section{LA AGENCIA DE LAS SOCIEDADES COMERCIALES}

En el anterior aparte se abordó el proceso de crecimiento del café en el departamento del Valle de Cauca y el impacto a partir del factor tierra durante las primeras décadas del siglo XX. Otro factor a considerar en este proceso fue la amplia gama de actores vinculados a la producción y comercialización del café, quienes dentro de la producción cafetera tenían diversa procedencia, capital y ocupaciones. Estos actores dieron inicio a actividades comerciales con la caficultura y encontraron significativas fuentes de renta-
Fuente: elaboración propia a partir: protocolos notariales de Notaría Primera de Sevilla (NPS), Notaría Única de Zarzal (NUZ) y de Notaría Única de Caicedonia (NUC). 
bilidad en relación con las oportunidades derivadas de la actividad global, las cuales iban desde las dinámicas en el inicio de la producción hasta la terminación del proceso mediante la exportación del grano.

En efecto, fue precisamente la variedad de agentes económicos vinculados al sector caficultor lo que contribuyó a jalonar el crecimiento de la producción de café a un ritmo vertiginoso. Por ello, se evidencia que en el proceso de consolidación no intervinieron pocos actores, sino que se trató de una cadena mucho más compleja. A lo largo de este apartado se tratará de caracterizar el proceso, al identificar las principales actividades y los actores económicos que intervinieron en la puesta en marcha de la comercialización cafetera de la región, tanto para su venta interna como para la salida hacia el exterior.

Las innovaciones presentadas en términos organizacionales fueron, de hecho, el resultado del papel ejercido por las sociedades comerciales en el funcionamiento de circuitos mercantiles a nivel regional, tanto de la comercialización de las importaciones como la salida de bienes agroexportables en todo el territorio. De una u otra forma, el despliegue de las actividades comerciales desde el conocimiento del sistema de información, brindaron la experiencia operacional en la conexión entre el mercado local y el internacional. Este enlace entre ambos mercados fue posible a través de las sociedades comerciales que tenían conexión directa con distintas sociedades en el extranjero. Otra estrategia desplegada fue el rol de los agentes locales establecidos en los mercados internacionales, donde se tejieron vínculos comerciales a través del eslabonamiento de casas matrices, sucursales, agentes comerciales, comisiones, acopiadores y productores, factores que terminaron articulando la producción con la comercialización y la logística de envío en el interior y el exterior. ${ }^{9}$ Entre las sociedades comerciales especializadas en la exportación cafetera o en el procesamiento de café molido -agroindustrial-, concurrieron organizaciones impulsadas por algunos de los individuos destacados de los centros comerciales de la región: Cali, Palmira, Buga y Sevilla; empresarios, sociedades y comerciantes diversificaron su capital e incursionaron en la exportación del grano (Delgado, 2014). gistros notariales pueden dar fe de ello, con la constitución de un número relevante de empresas a principios del siglo XX: 84 casas comerciales en funcionamiento. Este número simbolizaba la sólida inserción de Cali en el modelo económico mundial, pues la ciudad situó al comercio y a la producción de materias primas naturales o minerales, o de productos agropecuarios, como su principal actividad comercial y uno de los sectores más dinámicos en el entorno regional. 
Aquel proceso -que de acuerdo con lo analizado en este estudio fue exitoso- se aseguró a partir del despliegue de circuitos comerciales y redes extendidas, tanto a nivel regional como interregional, las cuales fomentaron la facilidad en la salida de la producción cafetera de los mercados internos. De lo anterior se desprende que en la línea de producción cafetera intervienen varios procesos que ratifican el posicionamiento comercial del producto final en el mercado internacional. Entonces, ¿cómo se organiza esté intercambio económico? Esta inquietud lleva a la necesidad de reconstruir el circuito económico establecido entre el Valle del Cauca y otros departamentos. ${ }^{10}$

Por otra parte, las casas de comercio que no participaron en la comercialización directa al exterior, sino que dirigieron sus esfuerzos aún mercado y una actividad muy puntual, el procesamiento en el mercado local y a nivel internacional, buscaron la tercerización del suministro de café con sociedades extranjeras que jugarían un rol determinante en la distribución. El mecanismo utilizado fue establecer contratos de exclusividad con la sociedad contratante del suministro de café en los que estipularon ciertas obligaciones que debían cumplirse, como la cantidad específica sobre tiempos, limitados con vigencia en promedio de entre seis y un año de lapso de entrega.

Ya sobre la década de 1920 se cuenta con varias casas comerciales y con contratos internacionales de la tan anhelada materia prima: Posada Tobón, Aristizábal y Piedrahita, Alfonso Vallejo y la compañía Vallejo de Industria y Comercio. Si bien, se fijaron contratos con casas extranjeras -lo cual permitió acceder a capital líquido internacional, es decir, pesos oro americanos-, se creó un vínculo dependiente entre los exportadores nacionales a través del suministro de crédito a los comisionistas. En este contexto, el papel de la banca nacional e internacional para la intermediación de las transferencias de suministro de créditos, cobros, giros de pago, etc. (Palacios, 2002), fue fundamental. La tabla 3 presenta las firmas con las que se acordaron los contratos.

10 Análisis que no ha sido tenido en cuenta por la historiografía regional y en el cual se tiene la necesidad de ir avanzando poco a poco. Por ende, este trabajo se apoyará en el estudio de las redes de intermediarios y las funciones de la intermediación económica y considerará de manera general todos los aspectos y los actores que contribuyeron dentro de la línea de la producción interna y la comercialización en los países demandantes de café. 
Tabla 3.

Contrato entre sociedades comerciales: Cali-Nueva York,

1920-1930

\begin{tabular}{|c|c|c|}
\hline Otorgante & Sociedad extranjera & Contrato \\
\hline Juri y Cobo & G. Amsinck y Cía. Inc. & Cuentas con café \\
\hline G. Lalinde G y Cía. & G. Amsinck y Cía. Inc. & Cuentas de café/crédito \\
\hline Alfonso Vallejo & G. Amsinck y Cía. Inc. & Cuentas de café/crédito \\
\hline Bohomer y Lizen & G. Amsinck y Cía. Inc. & Cuentas de café/crédito \\
\hline Tobón y Cía. & G. Amsinck y Cía. Inc. & Cuentas de café/crédito \\
\hline Caicedo Hijos & G. Amsinck y Cía. Inc. & Cuentas de café/crédito \\
\hline Compañía Alvallejo de Industria y Comercio & E. Canalizo y Company Incorporated & Cuentas de café/crédito \\
\hline Compañía Industrial Cafetera de Palmira & Banco de Londres y América del Sur & Cuentas de café/crédito \\
\hline Aristizábal y Piedrahita & The Vásquez Correa y Cía. Inc. & Cuentas de café/crédito \\
\hline
\end{tabular}

Fuente: elaboración propia con información de A. H. C., Ns, Escrituras n. ${ }^{\circ}$ 634,725; 1924: n. ${ }^{\circ}$ 306, 498. 1925: n. ${ }^{\circ} 170.1927: n^{\circ} 2231$

1928: n. ${ }^{\circ} 625,1845,2232.1928$.
Los nueve convenios firmados en la década de 1920 son una radiografía del fuerte vínculo con el mercado de los Estados Unidos, una de las conexiones más sólidas durante las primeras décadas del siglo XX, resultado de la presencia de firmas norteamericanas que hacían contratos en Colombia y estrechaban la relación comercial entre ambos países. ${ }^{11}$

Por otra parte, la estrategia de lograr estas alianzas comerciales entre ambos países se fundó por la inyección de capital a la economía local, ratificando el suministró de capital líquido que respaldaba los contratos firmados entre las partes. Las sociedades comerciales presentadas ofrecían ventajas, por ejemplo, el crédito conferido manejaba una tasa de interés bajo, comparado con la tasa crediticia de las instituciones bancarias en el país. Sin embargo, fueron créditos a corto plazo, más limitados sobre el pago; variaba de seis meses a un año de plazo, correspondiente al tiempo límite en la entrega de la producción cafetera.

Este suministro de capital líquido a nivel internacional se dio de manera vertical desde los contratos establecidos con casas comerciales extranjeras, las cuales inyectaron capital líquido al mercado nacional y a la firma

11 En los registros notariales consultados no se encontró este tipo de contratos especializados en el suministro de café con otros países en el mundo. 
exportadora de café. De allí, el capital se desplegó a los principales mercados internos a fin de afirmar las transacciones entre exportadores y productores de café, lo que garantizaría el constante suministro de café a los empresarios por parte de campesinos. Este esquema fue otro tipo de alianza necesaria para cumplir con la demanda establecida de los contratos entre las partes. Además, este tipo de contrato de pago por comisión entre campesinos y empresarios se renovaba año a año y eran asegurados con hipotecas. La tabla 4 muestra algunos contratos que evidencia este tipo transferencias en el mercado de Sevilla.
Tabla 4.

Ejemplo de contratos de proveedores de café en Sevilla 1920-1926

\begin{tabular}{|c|c|c|c|c|c|}
\hline $\begin{array}{c}\text { Vendedor o } \\
\text { contratado }\end{array}$ & $\begin{array}{c}\text { Contratante o } \\
\text { comprador }\end{array}$ & $\begin{array}{c}\text { Objeto del } \\
\text { contrato }\end{array}$ & Valor & Interés & Hipoteca \\
\hline Ignacio García & $\begin{array}{c}\text { Marco A. Rodríguez } \\
\text { (representación de } \\
\text { Rafael Jenaro Mejía } \\
\text { de Manizales) }\end{array}$ & $\begin{array}{c}\text { Contrato de } \\
\text { suministro de } \\
\text { café }\end{array}$ & $\begin{array}{c}200 \text { pesos } \\
\text { oro }\end{array}$ & No aplicó & $\begin{array}{c}\text { Hipoteca una casa en el } \\
\text { Jardín }\end{array}$ \\
\hline Juan Ceballos & Torres, Gómez y Cía. & $\begin{array}{c}\text { Contrato de } \\
\text { dos años, } \\
\text { suministro de } \\
\text { café }\end{array}$ & $\begin{array}{c}100 \text { pesos } \\
\text { oro }\end{array}$ & $1 \%$ Hipoteca unas mejoras, en \\
la Raquelita
\end{tabular}

A partir de los contratos presentados anteriormente se pueden identificar algunos aspectos generales, como quiénes eran los medianos y los grandes propietarios que suministraban café a comerciantes exportadores, así como quiénes tenían acceso a crédito para financiar el sostenimiento de sus plantaciones y cosecha, lo que daba posibilidad de obtener precios razonables por el producto (Arango, 1977). Se reconoce la influencia de casas comerciales del departamento de Caldas y del Valle del Cauca en la inyección de capital líquido por café o el trueque realizado por mercancías.
Fuente: elaboración propia a partir de Notaría Primera de Sevilla (1916-1926). 
El crédito era otorgado antes de recibir la cosecha, ante las necesidades básicas del agricultor para emprender tareas: comprar semillas o contratar algún peón. Así mismo, los intereses fueron bajos (oscilaban entre 1 y $3 \%$ ) y el promedio del valor prestado era entre 500 y 1.000 pesos oro, lo que ayudó a la dinamización de la economía campesina (Notaria Primera de Sevilla, Tomo 3, Escritura 205, 1925). De hecho, la extensión de crédito del exportador al productor o del pequeño negociante intermediario ha sido una parte esencial del sistema de mercado desde los primeros tiempos. El otorgamiento de crédito fue la estrategia principal para la compra de café. De este modo, el crédito circuló en la economía cafetera ante la carencia de formas institucionales bancarias en los mercados rurales.

\section{MEDIOS DE COMUNICACIÓN}

Por otra parte, la reducción de los costos de transporte y comunicación se lograrían a partir de las mejoras viales y fluviales realizadas. ${ }^{12}$ El desarrollo subsecuente de ferrocarriles y de transporte marítimo promovió el comercio y estimuló su concentración en los principales centros de mercado a medida que fue promovido por desarrollos institucionales, incluida la progresiva estandarización de las prácticas comerciales y el crecimiento de las organizaciones comerciales (Delgado, 2014).

Este mejoramiento fue la clave en el establecimiento de circuitos económicos creados y agenciados en conexión con los mercados internos de la región. Claramente, la optimización de la red de transporte permitió el vínculo de los centros de producción especializados, como las zonas cafeteras ubicadas en el norte de la región y en Caldas, las cuales estaban conectadas con los puertos fluviales y marítimos. Por ejemplo, el puerto de Buenaventura permitió la salida de la producción cafetera del suroccidente colombiano, con lo que departamentos como Cauca, Caldas y, principalmente, el Valle del Cauca consiguieron despachar el café por la aduana de este puerto. Un ejemplo de la conexión interregional se ve desde el despacho del grano de la región de Caldas, como se muestra en la tabla 5.

12 Un factor determinante para Casson y Lee (2011), dentro de los componentes que regulan el mercado, son los medios de comunicación. 


\begin{tabular}{|c|c|c|}
\hline Año & Bultos & Kilos \\
\hline 1920 & 254.111 & 17.787 .770 \\
\hline 1921 & 422.821 & 29.577 .470 \\
\hline 1922 & 242.641 & 16.964 .870 \\
\hline 1923 & 360.150 & 25.210 .500 \\
\hline 1924 & 355.152 & 24.860 .640 \\
\hline 1925 & 234.611 & 16.422 .770 \\
\hline 1926 & 184.181 & 12.892 .670 \\
\hline Total & $\mathbf{2 . 0 5 3 . 6 6 7}$ & $\mathbf{1 4 3 . 7 1 6 . 6 9 0}$ \\
\hline
\end{tabular}

Tabla 5.

Café procedente del departamento de Caldas transitando hacia el puerto de Buenaventura (19211926)

Estas condiciones, a su vez, permitieron establecer un circuito comercial integrado por el mejoramiento y la ampliación de la red ferroviaria que logró enlazar los mercados regionales a un gran mercado nacional. Por su parte, el alto volumen de carga que representó el transporte del café, unido al flujo comercial que generó la actividad exportadora, constituyeron una porción fija del producto que alimentó la red de comunicación a nivel interregional en el país (Toro, 2013); esfuerzos que condescendieron en la interconexión comercial de la producción y la distribución de los departamentos en el suroccidente colombiano (Cauca, Caldas y Valle del Cauca) con el Puerto de Buenaventura. Así mismo, la red de transporte mejoró notoriamente el intercambio entre las capitales y los centros urbanos, convirtiendo a Cali en una capital regional y punto de llegada comercial de la producción de tres departamentos con destino hacia el puerto de Buenaventura y desde allí al mercado mundial.

Para el funcionamiento de estas redes no solo fue necesario la estructura de comunicaciones, sino que además debía existir toda una red de organizaciones desplegadas por el territorio en pro de la organización de la logística necesaria para mover el café de las zonas donde se cosechaba. De esta forma, los intermediarios (sociedades/comerciantes) agenciaron toda la logística para generar una frecuencia de comercialización de todo tipo de bienes (despache de la carga de café y el envío de otros enseres) entre la región norte del Valle y Caldas. Las sociedades comerciales que prestarían esta logística fueron Garcés Patiño y Cía. y Llanos y Cía., desde su carácter individual o en representación de otros agentes económicos (Notaria Primera de 
Cali, Tomo, 4, escritura 594, 1924). Este tipo de sociedades tenían su centro de operaciones a lo largo de los principales puertos de la región ${ }^{13}$ (Notaria Primera de Cali, Tomo 10, escritura 1021, 1924).

Las mismas firmas recibían el cargamento, ya fuera en Puerto Isaac o en Puerto Mallarino, donde desplegaban toda la operación por medio de representantes de la firma y oficinas en los principales puertos en la ruta de navegabilidad y aseguraban el despache y la descarga de los bultos de café de varios empresarios. Esto se puede verificar a partir del viaje realizado en 1924, donde zarpaba de Puerto Mallarino el Vapor Cabal en su viaje número 43 con llevaba 673 bultos de carga de varios puertos y pertenecientes a varios empresarios cafeteros (cuadro 1). El cuadro 1 evidencia de nuevo la importancia de los comisionistas que facilitaban el envío del café a lo largo del circuito. Así mismo, demuestra la agencia de sociedades comerciales caleñas conectadas con los centros de producción de Caldas y Antioquia y la presencia de café proveniente de Medellín, que también era despachado por el puerto de Buenaventura.

\section{Cuadro 1.}

Características de la carga en el viaje de caldas a Cali, 1924

60 sacos de café almendra, marca Bank Trust New York, Andes, Armenia. Excelso por cta. de Banco del Ruíz de Manizales y también embarcado por Garcés Patiño \& Co. y a la orden de los mismos en Puerto Isaac.

138 sacos café almendra marca Gonzalo fantasía, Medellín New York y 10 sacos marca Gonzalo consumo New York, total 148 sacos cta. de Rafael Genaro Mejía y despachado también por Garcés Patiño \& Cía. a los mismos en Puerto Isaac.

60 sacos de café almendra sin escoger por cuenta de Caicedo Puente \& Co. Despachados por los mismos y a su orden de Puerto Mallarino.

Fuente: Notaría Segunda de Cali,

Tomo 10, Escritura 1021, 1924.
Una de las líneas vitales del tejido interregional fue trazada por el Ferrocarril del Pacífico en la conexión sur-norte, la cual enlazó los departamentos del Cauca y del Valle del Cauca y vinculó a sus capitales, Cali y Popayán, que se encontraban a 159 kilómetros de distancia; esto también permitió la movilidad de mercancías con el departamento del Cauca. Internamente, el Ferrocarril del Pacífico desembotelló de manera eficiente al Valle del Cauca y para 1930 había conseguido integrar toda la economía local desde el sur hasta el norte. Así mismo, la conexión interna de los mercados regionales consiguió movilizar y comercializar la producción de cada uno de los

13 Puertos como La Virginia, Puerto Caldas, Puerto de Toro y Puerto Mallarino. 
municipios a nivel regional, creando una red de comercio tanto de materias primas como de mercancías manufacturadas.

Precisamente, la ruta más importante del ferrocarril fue Buenaventura-Cali-Cartago, puesto que integró toda la zona centro del departamento con el puerto -de oeste a este-, bajando desde Tuluá, Buga, Yumbo y La Cumbre hasta Dagua, Cisneros y Córdoba, para finalmente llegar a Buenaventura (figura 2). La tercera línea férrea articuló todo el departamento con la zona norte y arrancó en la estación de Zarzal, a 304 kilómetros de Buenaventura, penetrando el territorio de Caldas y las estribaciones del flanco occidental de la cordillera central o del Quindío de manera ascendente (Monsalve, 1927).

Figura 2.

Ruta del ferrocarril del Pacífico Caldas-Buenaventura, año 1930

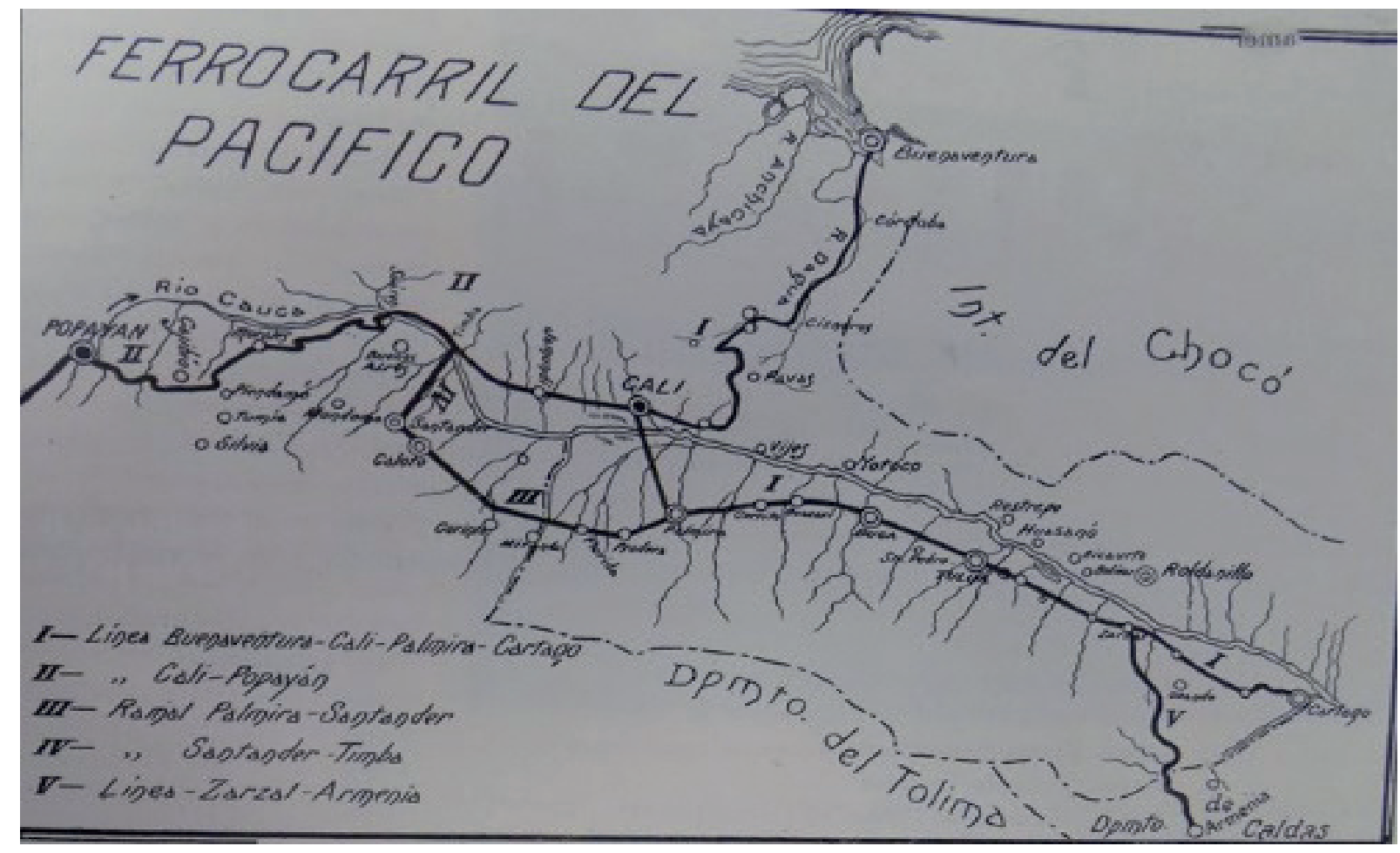

De esta manera, las actividades desplegadas a nivel interregional convirtieron a Cali en un lugar estratégico que concentraba la llegada y la salida Fuente: (Monsalve, 1927). de gran volumen de mercancías y la producción de bienes agrícolas con destino al comercio exterior. En este sentido, la estación del Ferrocarril del Pacífico en Cali fue la más importante de la toda la ruta ferroviaria, en doble vía: en cuanto al movimiento de mercancías derivadas de las importaciones llegadas al puerto de Buenaventura que, posteriormente, eran introducidas hacia el interior del departamento y en lo relacionado con las exportaciones realizadas a nivel interregional. 


\section{CONCLUSIONES}

El estímulo y desarrollo de la producción cafetera en el Valle del Cauca fue inducido bajo una demanda constante del grano a nivel internacional que conllevó al volcamiento de diferentes actores al vincularse a los frutos y la especulación que generó la actividad cafetera durante los primeros 30 años del siglo XX. Esto permitió que se gestarán una serie de especializaciones dentro del circuito económico creado en la región para lograr la exportación del grano, como sucedió con la producción, el procesamiento y la logística de transporte del producto del cultivo de café. A partir de la conjugación de estas actividades, el modelo agroexportador en la región del Valle del Cauca resultó ser exitoso.

Sin embargo, como se expuso a lo largo del artículo, para que se logrará funcionalidad dentro del sector no solo fue necesario que existiera una demanda del grano, sino que también fue necesaria una organización interna y multifactorial para el desarrollo de la economía cafetera, donde se destacaron dos pilares fundamentales. El primero, dentro del proceso de transformación agrícola del departamento (en niveles productivos), dado a partir de la expansión de la frontera agraria; donde se desarrolló un mercado de tierras con varias operaciones; y segundo el rol jugado por sociedades comerciales cafeteras que se encargaron de comercializar el producto.

En cuanto a la estructura y distribución de la tierra, a partir del mercado de tierras se creó la base sobre la cual se pudo legalizar la propiedad, ampliar la frontera agrícola de la región y aumentar la producción a nivel regional. Dicho mercado demostró condiciones principales que lo hicieron especial, como el hecho de que no fuese exclusivo de empresarios territoriales sino abierto a todos los actores.

Por otra parte, la concurrencia de sociedades comerciales cafeteras permitió la presencia de un actor que facilitaría la comercialización a nivel regional hacia los mercados de demanda. Así, fue posible adelantar tres procesos centrales: (i) innovar en términos estructurales y organizativos; (ii) apoyar la actividad cafetera mediante el establecimiento de redes de comercialización para poder dirigir la producción local hacia los mercados de consumo nacionales y extranjeros, creando un tejido económico entre Sevilla, Manizales, Cali y Nueva York; (iii) no solo establecer redes de comercialización hacía los clientes, sino que a los cultivadores y los comerciantes locales sevillanos les brindaron, a cambio del café producido, créditos en 
forma de dinero, mercancías o créditos hipotecarios para comprar propiedades o mejorar las que tenían.

\section{REFERENCIAS}

\section{Archivos y fuentes primarias}

\section{Archivos públicos y bibliotecas}

Archivo Histórico Municipal de Cali (AHMC)

Archivo de la Notaría Primera de Sevilla (NPS)

Archivo de la Notaría Única de Zarzal (NUZ)

Biblioteca Luis Ángel Arango

Biblioteca Mario Carvajal

Biblioteca Nacional de Colombia

\section{Hemerografía y publicaciones seriadas}

Anuario Estadístico del Valle del Cauca, 1938, 1938, 1945.

Boletín Estadístico del Valle del Cauca, 1917.

Boletín Estadístico Municipal Cali, 1920-1930.

\section{Referencias}

Arango, M. (1977). Café e industria 1850-1930. Bogotá: Carlos Valencia Editores.

Casson, M., \& Lee, J. (2011). The origin and development of markets: A Business History perspective. Business History Review, 85, 9-37. https://doi. org/10.1017/S0007680511000018

Delgado, B. (2014). Prácticas empresariales en los negocios de la familia Carvajal Borrero: inicio, desenvolvimiento, consolidación y crecimiento en Cali, 1880-1939 (tesis de pregrado). Departamento de Historia, Universidad del Valle, Cali, Colombia.

Gordillo, J. (2001). Café y crecimiento económico regional: el antiguo Caldas. Manizales: Editorial Universidad de Caldas.

Gelman, J. (2009). ¿Crisis postcolonial en las economías sudamericanas? Los casos de Rio de la Plata y Perú. En E. Llopis \& C. Marichal (coord.). Latinoamérica y España, 1800-1850: un crecimiento económico excepcional (pp. 25-64). Madrid: Instituto de Investigaciones Dr. José María Luis Mora. 
Lewis, C. M. (2008). Economías de exportación. En A. Castillero \& A. Kuethe (eds.). Historia General de América Latina, vol. VII (pp. 79-109). Madrid: Unesco/Trota.

Londoño, J. (2003). Lisando Caicedo: Un empresario territorial caucano. En C. Dávila-Ladrón-de-Guevara (ed.). Empresas y empresarios en la historia de Colombia. Siglos XIX-XX (407-441). Bogotá: Norma.

Londoño, J. (1993). De San Luis a Sevilla (tesis de pregrado). Universidad del Valle, Cali, Colombia.

Legrand, C. (1988). Colonización y protesta campesina en Colombia. Bogotá: Universidad Nacional de Colombia.

Machado, A. (1975). Relaciones de producción en la economía cafetera, 1930. Ideología y sociedad, n. d., 64-86.

Machado, A. (2002). De la estructura agraria al sistema agroindustrial. Bogotá: Universidad Nacional de Colombia.

Monsalve, D. (1927). Colombia cafetera. Barcelona: Henrich y Cía.

Ocampo, J. A. (1965). Café, industria y macroeconomía, ensayos de historia económica colombiana. Bogotá: Banco de la República.

Ocampo, J. A. (2015). Café industria y macroeconomía: ensayos de historia económica colombiana. Bogotá: Fondo de Cultura Económica.

Palacios, M. (2002). El Café en Colombia 1850-1970 una historia económica, social y política. Bogotá: Planeta. https://doi.org/10.2307/j.ctv51304h

Posada, J. (1918). Libro azul de Colombia. Nueva York: The J. J. Little \& Ives Comp.

Quejada, J. C. (2016). Manejo estatal de baldíos: factor de crecimiento en el departamento del Valle del Cauca, 1910-1920. Anuario Colombiano de Historia Social y de la Cultura, 43(1), 135-163. doi: https://doi. org/10.15446/achsc.v43n1.55067

Quiceno, L. A. (2007). La formación histórica de Sevilla (Valle), 1903-1920 (tesis de pregrado). Universidad de Antioquia, Medellín, Colombia.

Ramírez, R. (2001). La Aurora: Modelo de hacienda cafetera agroexportadora. Líbano-Colombia, 1907-1934. Cuadernos de Desarrollo Rural, 46, 75-100.

Ramírez, R. (1999). De la distribución de baldíos a la consolidación de una región cafetera: dinámica comercial y estructuras agrarias en El 
Líbano, Tolima, 1886-1897. Anuario Colombiano de Historia Social y de la Cultura, 26, 83-114.

Ramírez, R. (2004). Formación y transformación de la cultura laboral cafetera en el siglo XX. Medellín: La Carreta Histórica

Ramírez, R. (2008). Historia laboral de una hacienda cafetera: La Aurora, 18821982. Medellín, La Carreta Editores.

Santos, A., \& Sánchez, H. (2015). Tierras públicas y privadas para la cría de ganado y cultivos de café en una zona de frontera del Caribe colombiano: Valledupar (Magdalena), 1920-1940. Memorias. Revista Digital de Historia y Arqueología desde el Caribe, 11(27), 244-275.

Santos, A., \& Sánchez, H. (2010). La irrupción del capitalismo agrario en el Valle del Cauca. Cali: Universidad del Valle.

Toro, J. (2013). Economía cafetera y el desarrollo económico en Colombia. Bogotá: Universidad de Bogotá Jorge Tadeo Lozano.

Vásquez, E. (2001). Historia de Cali en el siglo 20: sociedad, economía, cultura y espacio. Cali: Universidad del Valle.

Valdivia, L. (1992). Economía y espacio en el Valle del Cauca. Cali: Universidad del Valle.

Viloria, J. (1998). Café en la Sierra Nevada de Santa Marta: aspectos históricos. En L. Martínez \& H. Sánchez (eds.). Indígenas poblamiento, política y cultura en el departamento del Cesar (n. d.). Valledupar: Ediciones Unicesar.

Zuluaga-Jiménez, C. (2012). Historiografía empresarial e industrial sobre el Valle del Cauca, 1950-2007. Revista de Historia Regional y Local, 4(8), 316-366. https://doi.org/10.15446/historelo.v4n8.31962 